\title{
Influence of Terpenic Oil on Flotation Behavior of Sphalerite and Implication for the Selective Separation
}

\author{
Bo Yang $\mathbb{D},{ }^{1,2,3}$ Xian Xie $\mathbb{D}^{3,4}$ Xiong Tong, ${ }^{3,4}$ and Lingyun Huang $\mathbb{D}^{3,4}$ \\ ${ }^{1}$ Faculty of Environmental Science and Engineering, Kunming University of Science and Technology, Kunming 650093, China \\ ${ }^{2}$ Kunming University, Kunming 650214, China \\ ${ }^{3}$ State Key Laboratory of Complex Nonferrous Metal Resources Clean Utilization, Kunming University of Science and Technology, \\ Kunming 650093, China \\ ${ }^{4}$ Faculty of Land Resource Engineering, Kunming University of Science and Technology, Kunming 650093, China
}

Correspondence should be addressed to Xian Xie; xianxie2008@kmust.edu.cn and Lingyun Huang; hly0510@126.com

Received 5 September 2021; Revised 19 October 2021; Accepted 12 November 2021; Published 31 December 2021

Academic Editor: Selvaraju Narayanasamy

Copyright (c) 2021 Bo Yang et al. This is an open access article distributed under the Creative Commons Attribution License, which permits unrestricted use, distribution, and reproduction in any medium, provided the original work is properly cited.

\begin{abstract}
Terpenic oil (TO) is commonly used as a flotation frother for the selective separation of sulfide minerals. As a frother, most reports have mainly focused on its effect on froth stability and froth entrainment, whereas its influence on the floatability of sulfide minerals has received little attention. In this work, the influence of TO on the flotation behavior of sphalerite was investigated by using microflotation tests, contact angle and zeta potential measurements, and FT-IR and SEM-EDS analyses. Microflotation tests conducted in a modified Hallimond tube indicated that compared with the collector potassium butyl xanthate (KBX), the flotation recovery of sphalerite was significantly increased when TO was added to the pulp, but the recovery of $\mathrm{Cu}$-activated sphalerite with the addition of TO was lower than that with the addition of KBX. Contact angle measurements demonstrated that the contact angle of sphalerite was distinctly increased by the addition of TO, but the contact angle of sphalerite treated with $\mathrm{TO}$ was lower than that treated with $\mathrm{KBX}$ after $\mathrm{Cu}$ activation. Zeta potential measurements demonstrated that the zeta potential of sphalerite particles was slightly decreased when treated with TO, and the isoelectric point (IEP) was decreased from 3.3 to 3.1 due to the interaction of TO with sphalerite particles. FT-IR and SEM-EDS confirmed that TO could be adsorbed on the sphalerite surface on the formation of the oil film due to its low solubility, thereby increasing the surface hydrophobicity of the sphalerite. In addition, the TO absorbed on the surface acts as a bridging role and promotes the hydrophobic agglomeration of sphalerite particles. These results suggest that except for froth entrainment, the influence of TO on the flotation behavior of sphalerite may be another reason for the misreporting of sphalerite in concentrates.
\end{abstract}

\section{Introduction}

In the mineral processing industry, froth flotation is the most common technology for the selective separation of valuable minerals from gangue minerals $[1,2]$. In froth flotation, the hydrophobic mineral particles can adhere to air bubbles dispersed in the pulp and transfer from the pulp region to the froth layer, while the hydrophilic mineral particles remain in the pulp and are collected in the tailings. These air bubbles dispersed in the pulp region play an important role in froth flotation [3-7]. Generally, the finer the air bubbles are, the higher the flotation separation effi- ciency is. Therefore, to generate finer and more stable air bubbles in the pulp, a surfactant called the frother usually needs to be added to the pulp prior to flotation separation $[8,9]$. Organic reagents such as methyl isobutyl carbinol (MIBC), polypropylene glycol methyl ether (DF-200), and polypropylene glycol (PPG) are widely used as flotation frothers [10-12]. As a surfactant, the foaming ability of a frother is usually determined by its molecular structure, which commonly consists of nonpolar hydrocarbyl and polar groups $\left(-\mathrm{OH},-\mathrm{COOH},-\mathrm{C}=\mathrm{O},-\mathrm{OSO}_{2}\right.$, and $\left.-\mathrm{SO}_{2} \mathrm{OH}\right)$. In the pulp, the frother molecule can be oriented at the gas-liquid interface with the nonpolar hydrocarbyl inserted 
in the gas phase and polar groups inserted in the water phase. The interfacial tension of the gas-liquid interface is significantly decreased by the addition of the frother, which can prolong the dwell time of bubbles and prevent bubbles from bursting $[13,14]$.

At present, most literatures on the flotation frother have mainly focused on its effect on froth entrainment and froth phase stability. Froth entrainment is a common phenomenon in mineral flotation and has a negative effect on the selectivity of flotation separation; the undesired mineral particles are transferred to the froth phase and concentrates. The froth entrainment caused by air bubbles is illustrated in Figure 1 [5, 15-17]. Many studies have indicated that the degree of entrainment is controlled by various factors, such as water recovery, solids percentage, gas flow rate, and froth height. Among these factors, water recovery is considered the most important factor affecting the entrainment degree, which is directly related to the molecular structure of the frother. An increase in the recovery of water usually results in the increasing number of undesired mineral particles in concentrates, which leads to a decrease in the grade of concentrates [18]. Froth entrainment is regarded as the predominant reason for the misreporting of the undesired mineral particles in concentrates.

Terpenic oil (TO), a mixture of terpene alcohol (TA) and nonpolar oil, is widely used as a flotation frother in China because of excellent foaming performance and low cost. TO is mainly obtained from the hydration reaction of turpentine, which is derived from pine wood distillation or byproducts of the chemical industry [19-21]. TA, with a content of $80 \%$ to $85 \%$, is the predominant component in TO that acts as a frother. The molecular structure of TA is shown in Figure 2 [22].

In industrial flotation operation, more stable and finer air bubbles can be obtained by the addition of TO. However, it is found that the type of frother has an important effect on the selective flotation of sulfide minerals. Usually, a higher grade of concentrates was obtained when using MIBC instead of TO as the flotation frother, which can be attributed to the different entrainment degrees of both $[23,24]$. Therefore, more attention was paid to the influence of TO on froth entrainment; the influence of TO on the floatability of sulfide minerals is commonly ignored. In our flotation tests, an obvious phenomenon was observed for the microflotation of sphalerite. The recovery rate of sphalerite was significantly improved when the frother TO was added to the pulp, even without the addition of an activator or collector. In our flotation tests, the sphalerite particles floated by the froth entrainment can be excluded because a modified Hallimond flotation tube was used. Therefore, we speculated that the frother TO may interact with the sphalerite surface, leading to an increase in the flotation recovery of sphalerite. The objective of this study was to investigate the influence of frother TO on the flotation behavior of sphalerite, and the results may be helpful for explaining the misreporting of sphalerite in concentrates other than that caused by froth entrainment.

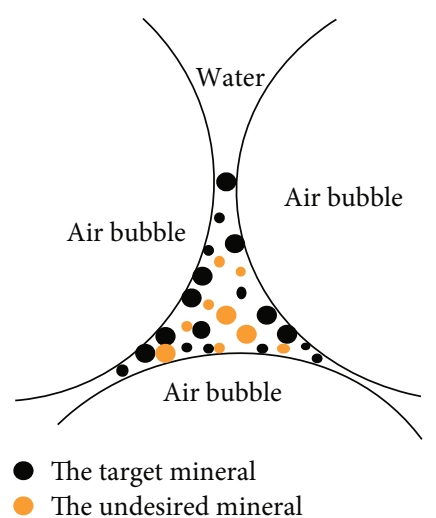

FIGURE 1: Schematic of froth entrainment in flotation.

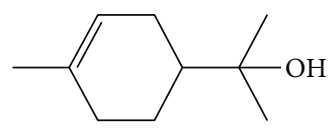

Figure 2: Molecular structure of TA.

\section{Materials and Methods}

2.1. Materials. The highly mineralized sphalerite samples used in this work were obtained from Huize Lead \& Zinc Mines, Yunnan Province, China. After crushing the samples with a hammer and manually removing gangue minerals, the samples were dry-ground in a porcelain ball mill and dry-screened using nylon sieves to obtain the desired particle size. The samples were then sealed in a polyethylene bag and stored in a refrigerator at a temperature of $-5.0^{\circ} \mathrm{C}$ to prevent surface oxidation [7]. The chemical composition and X-ray diffraction analysis of the sphalerite samples are given in Table 1 and Figure 3, respectively. These results indicate that the sphalerite samples used in this study were of high purity.

The frother TO and the collector potassium butyl xanthate $(\mathrm{KBX})$, both of industrial purity, were used in this study. For comparison, TA (the predominant component in TO) of analytical purity was purchased from Shanghai Aladdin Biochemical Technology Co., Ltd., China. In addition, $\mathrm{HCl}$ and $\mathrm{NaOH}$ of analytical purity from Tianjin No. 3 Chemical Reagent Factory were used as the $\mathrm{pH}$ regulator. Deionized water having a resistivity of $18.25 \mathrm{M} \Omega \mathrm{cm}^{-1}$ was used in all the tests.

2.2. Microflotation. Microflotation tests were conducted in a modified Hallimond flotation tube (shown in Figure 4) with an inner diameter of $1.5 \mathrm{~cm}$. By using the modified flotation tube, any froth entrainment was prevented because only one $\mathrm{N}_{2}$ bubble could pass through the flotation tube at a time. Therefore, the change in the flotation recovery of the mineral could be attributed to the influence of TO when TO was added to the pulp. For each flotation test, $2.0 \mathrm{~g}$ of a sphalerite sample of size $-0.074 \mathrm{~mm}$ to $+0.048 \mathrm{~mm}$ was used. First, the sphalerite sample was mixed with $20 \mathrm{~mL}$ of deionized water in a $50 \mathrm{~mL}$ beaker, and the $\mathrm{pH}$ of the suspension was adjusted to the specified $\mathrm{pH}$ using $0.01 \mathrm{~mol} / \mathrm{L} \mathrm{HCl}$ or $\mathrm{NaOH}$ solutions. Next, reagents at the specified dosage were 
TABLE 1: Chemical compositions of sphalerite used in this study.

\begin{tabular}{lccccc}
\hline Elements & $\mathrm{Zn}$ & $\mathrm{Fe}$ & $\mathrm{S}$ & $\mathrm{Pb}$ & $\mathrm{SiO}_{2}$ \\
\hline Sphalerite & 64.18 & 1.16 & 34.21 & 0.13 & 0.32 \\
\hline
\end{tabular}

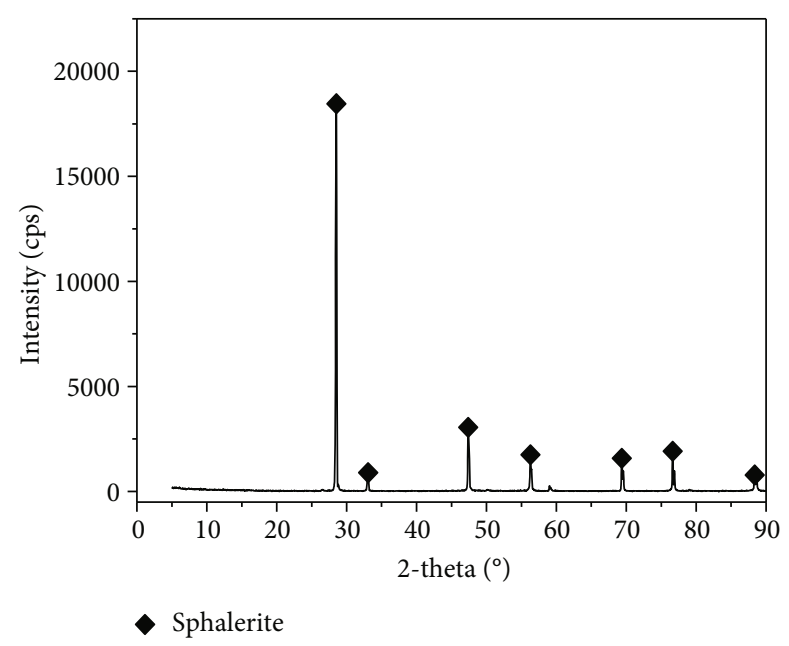

FIgURE 3: X-ray diffraction spectrum of sphalerite.

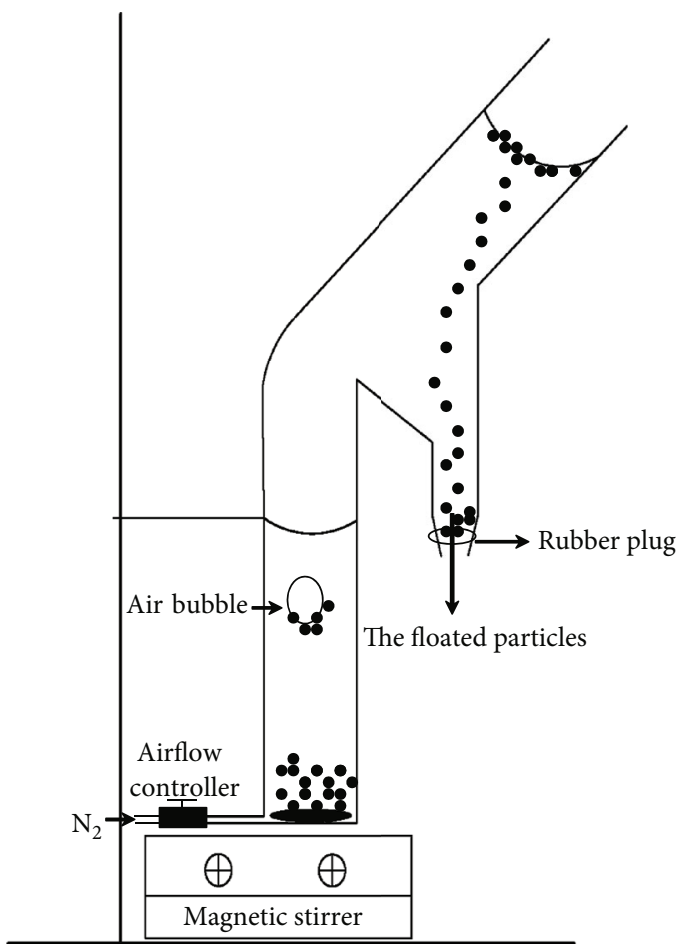

FIGURE 4: Schematic of the Hallimond tube used in the flotation tests.

added and conditioned for $3 \mathrm{~min}$. After conditioning, the pulp was quickly transferred to the flotation tube and floated for $5 \mathrm{~min}$ at an $\mathrm{N}_{2}$ flow rate of $0.005 \mathrm{dm}^{3} / \mathrm{min}$ (86 bubbles/ $\mathrm{min})$. Finally, the floated and nonfloated sphalerite particles were collected, filtered, dried at $40^{\circ} \mathrm{C}$, and weighed to calculate the recovery. The calculation method for recovery of sphalerite is shown as follows:

Recovery $=\frac{\text { mass of the floated minerals }}{\text { mass of the floated and nonfloated minerals }} \times 100 \%$.

All experiments were repeated three times under the same conditions, and the recovery value reported in this study is the average value.

\subsection{Analysis Techniques}

2.3.1. Contact Angle Measurements. Contact angle measurements were performed to investigate the influence of TO on the surface hydrophobicity of sphalerite. Measurements were carried out at room temperature $\left(25^{\circ} \mathrm{C}\right.$ and $67 \%$ relative humidity) by using a JY-82-type contact angle analyzer manufactured by Chengde Test Factory, China. The highly mineralized sphalerite sample was cut to obtain a measured area of $1.2 \mathrm{~cm} \times 1.2 \mathrm{~cm}$. Before measurement, the working surface was created by polishing the surface with $\mathrm{Al}_{2} \mathrm{O}_{3}$ sandpaper. After polishing and washing with deionized water, the surface was treated with the solution for $3 \mathrm{~min}$ and dried for further measurement. Subsequently, a microsyringe was used to drop $5 \mu \mathrm{L}$ of deionized water onto the surface, and the contact angles on both sides of the droplet were measured. Each sample was measured three times, and the value reported in this work is the average value.

2.3.2. Zeta Potential Measurements. The zeta potentials of sphalerite with and without the addition of TO or TA were measured using a zeta potential analyzer (Malvern Zetasizer Nano ZS90, Malvern Panalytical Ltd., Britain). The sphalerite samples were ground to a particle size of less than $0.010 \mathrm{~mm}$. The mineral suspension was prepared by adding $0.2 \mathrm{~g}$ of sphalerite samples to the $20 \mathrm{~mL}$ deionized water, and the $\mathrm{pH}$ of the suspension was adjusted by using $0.01 \mathrm{~mol} / \mathrm{L} \mathrm{HCl}$ and $\mathrm{NaOH}$ solutions. Then, the given dosage of TO or TA was added to the suspension and conditioned for $2 \mathrm{~min}$. After conditioning, $5.0 \mathrm{~mL}$ of the suspension was quickly transferred to the sample cell of the apparatus by using a syringe and subjected to zeta potential measurement. All tests were repeated three times with the same conditions, and the maximum standard deviation for the three measurements was within $\pm 2.0 \mathrm{mV}$.

2.3.3. FT-IR Spectrum. The FT-IR spectra of sphalerite were analyzed using a Nicolet Avatar 330 FT-IR spectrometer (Thermo Fisher Scientific Inc., USA). A sphalerite sample with a particle size of $-0.010 \mathrm{~mm}$ was first conditioned with a specified dosage of TO or TA for $3 \mathrm{~min}$. After conditioning, the pulp was filtered and dried under vacuum at $30^{\circ} \mathrm{C}$. The solid particles were then mixed with $\mathrm{KBr}$. After flaking, the samples were subjected to FT-IR analysis. A wavelength range of $4000-400 \mathrm{~cm}^{-1}$ was employed in the FT-IR analysis.

2.3.4. SEM-EDS. Scanning electron microscopy equipped with an energy-dispersive spectrometer (SEM-EDS, Quanta-200, FEI Company, USA) was employed to investigate the hydrophobic agglomeration of sphalerite particles. 


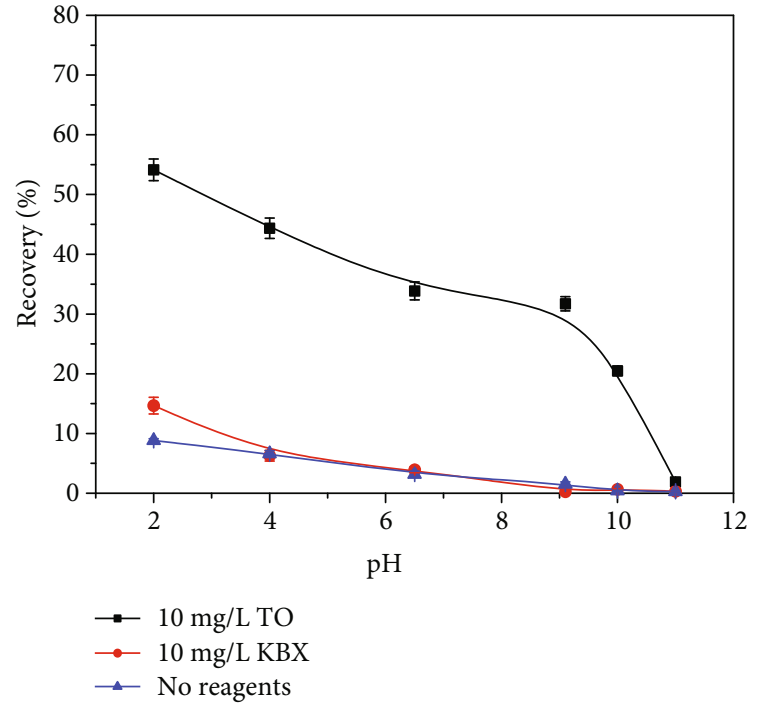

(a)

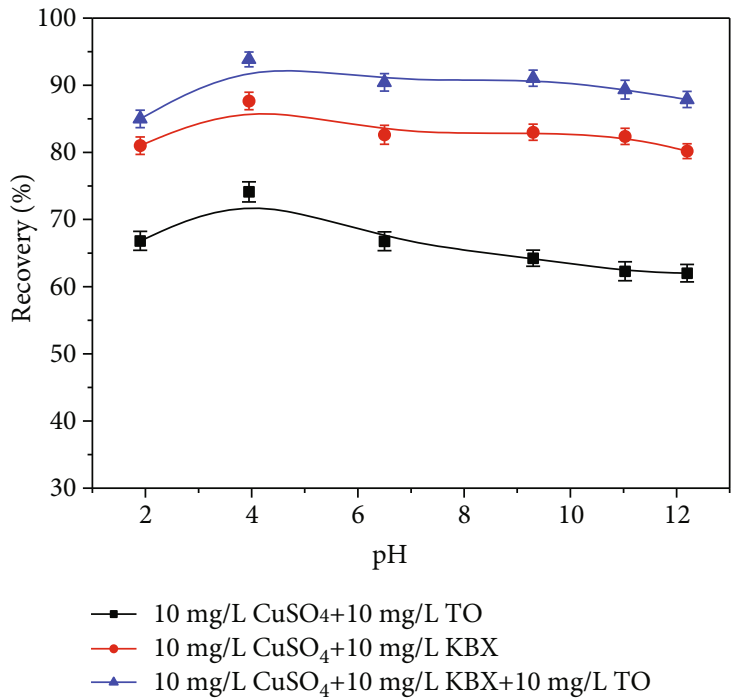

(b)

FIgURE 5: Effect of TO on the flotation behavior of sphalerite: (a) without activation by $\mathrm{CuSO}_{4}$ and (b) activated by $10 \mathrm{mg} / \mathrm{L} \mathrm{CuSO}$.

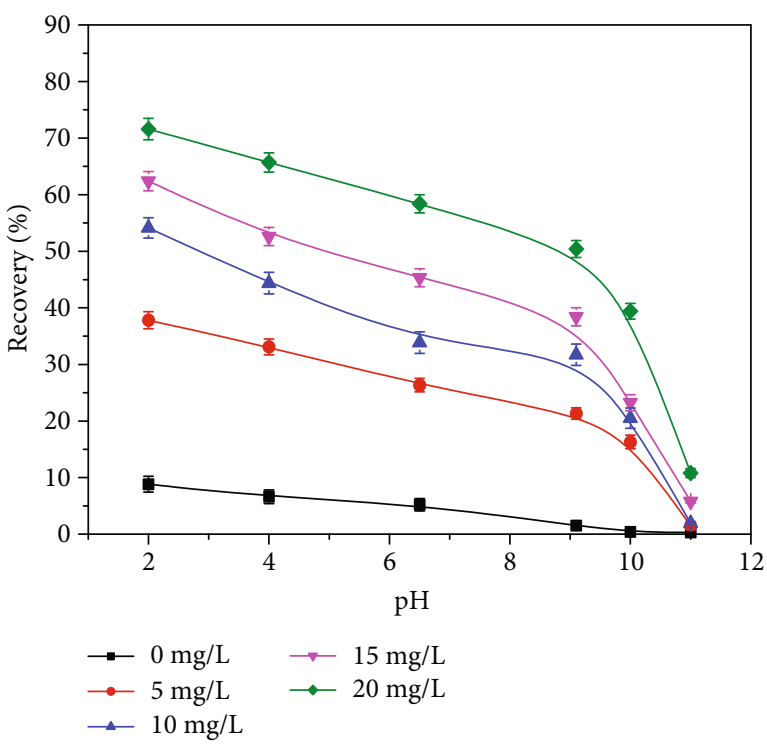

Figure 6: Effect of TO dosage on the recovery of sphalerite.

First, the sphalerite sample with particle sizes of $-0.074 \mathrm{~mm}$ to $+0.048 \mathrm{~mm}$ was cleaned for $5 \mathrm{~min}$ using an ultrasonic cleaner to remove any fine particles adhering to the sphalerite surface. Subsequently, the sphalerite sample was mixed with $20 \mathrm{~mL}$ of deionized water, and TO was added to the pulp and conditioned for $3 \mathrm{~min}$. Then, the sample was filtered and dried at room temperature $\left(25^{\circ} \mathrm{C}\right)$. Finally, the sample was subjected to SEM-EDS analysis.

\section{Results and Discussion}

3.1. Effects of TO on the Flotation of Sphalerite. The effects of $\mathrm{TO}$ on the flotation behavior of sphalerite and $\mathrm{Cu}$-activated sphalerite as a function of $\mathrm{pH}$ are shown in Figure 5. For comparison, the flotation behavior of sphalerite with $\mathrm{KBX}$ as a collector is also shown in Figure 5.

As shown in Figure 5(a), the flotation recovery of sphalerite without activation by $\mathrm{CuSO}_{4}$ was less than $10 \%$ at all the studied $\mathrm{pH}$ ranges, and the flotation recovery declined with increasing $\mathrm{pH}$. When $10 \mathrm{mg} / \mathrm{L} \mathrm{KBX}$ was added to the pulp, the flotation recovery of sphalerite increased slightly in the acidic $\mathrm{pH}$ range of 2.0 to 4.0 , owing to the poor response of $\mathrm{KBX}$ to the unactivated sphalerite surface. However, when $10 \mathrm{mg} / \mathrm{L} \mathrm{TO}$ was added to the pulp, the flotation recovery of sphalerite was significantly increased at the $\mathrm{pH}$ ranges of 2.0 to 10.0 compared with the addition of $10 \mathrm{mg} /$ $\mathrm{L}$ KBX or no reagents. The maximum recovery value of $55.2 \%$ was achieved at $\mathrm{pH}$ of 2.0 , and then, the recovery gradually decreased with increasing $\mathrm{pH}$. Overall, the flotation recovery of sphalerite with the addition of TO was remarkably higher than that with the addition of KBX or no reagents.

Figure 5(b) presents the flotation behavior of sphalerite activated by $\mathrm{CuSO}_{4}$ with the presence of $\mathrm{KBX}$ or TO in the pulp. For both KBX and TO, the flotation recovery of sphalerite displays a pronounced increase with the activation of $\mathrm{CuSO}_{4}$. The recovery of sphalerite with the addition of KBX was distinctly higher than that with the addition of $\mathrm{TO}$ at all the studied $\mathrm{pH}$ ranges, indicating that KBX plays a predominant role in the floatability of $\mathrm{Cu}$-activated sphalerite. With increasing $\mathrm{pH}$, only a slight decline in recovery was observed with the addition of TO. In addition, the flotation recovery of sphalerite with both KBX and TO was remarkably higher than that obtained by the addition of KBX or TO alone, which indicated that there was a synergistic effect between KBX and TO on the sphalerite surface. These results indicate that TO has a noteworthy influence on the flotation behavior of sphalerite.

The effect of the TO dosage on the recovery of sphalerite as a function of $\mathrm{pH}$ is shown in Figure 6. 


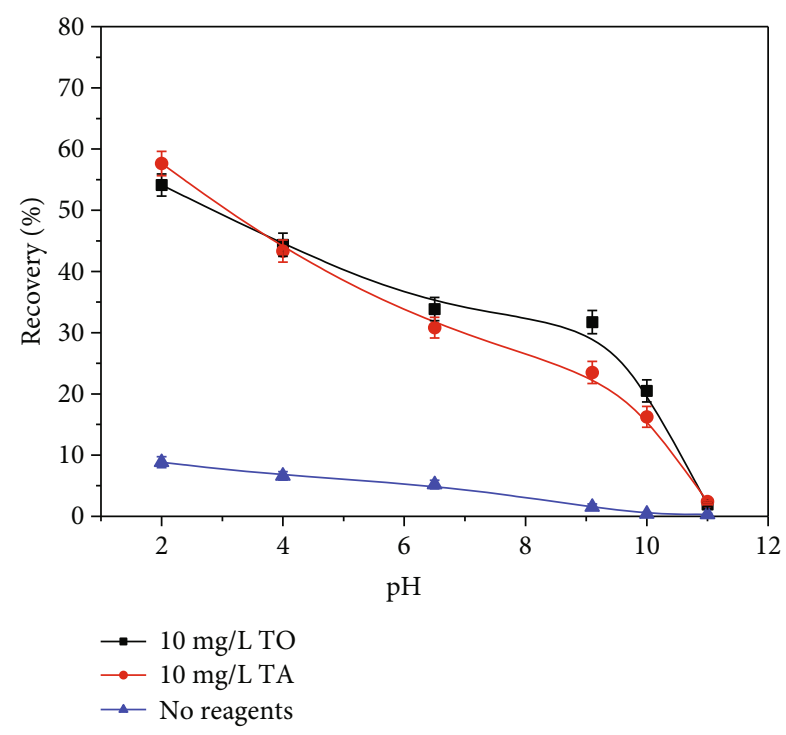

FIGURE 7: Effect of TA on the flotation behavior of sphalerite.

Figure 6 shows that the flotation recovery of sphalerite was remarkably increased with increasing dosages of TO in the pulp. At $\mathrm{pH}$ ranges from 2.0 to 10.0 , the greater the TO dosage, the greater the recovery of sphalerite. However, the recovery of sphalerite gradually decreased with the increase in $\mathrm{pH}$.

TO, as a mixture of TA and nonpolar oil, has been widely used as a flotation frother in Chinese mineral processing plants. The effect of nonpolar oils such as kerosene and diesel oil on the floatability of sulfide minerals has been discussed in some studies and applied in early oil flotation. The selectivity and collecting ability of nonpolar oil as a collector are insufficient because of its lower solubility and selectivity [25]. TA is a type of surfactant and the predominant component in TO, but its effect on the flotation behavior of sulfide minerals has received little attention. To further investigate the effect of $\mathrm{TO}$ on the flotation behavior of sphalerite, TO was replaced with an analytical-purity TA. The influence of TA on the flotation behavior of sphalerite as a function of $\mathrm{pH}$ is shown in Figure 7.

As shown in Figure 7, the recovery tendency of sphalerite with the addition of TA was similar to that obtained with the addition of TO, which suggested that TA also has an influence similar to that of TO on the flotation behavior of sphalerite. This result demonstrates that, except for the nonpolar oil in $\mathrm{TO}$, the predominant component TA of TO also has an important influence on the flotation behavior of sphalerite.

In our microflotation tests, the flotation recovery of sphalerite was lower than that reported by Fornasiero and Ralston, which can be attributed to the different methods used in the microflotation tests [26]. In the study by Fornasiero and Ralston, a flotation machine was used in which the froth entrainment was remarkable and unpreventable. However, in this work, the froth entrainment was prevented because of the utilization of a modified Hallimond tube, and the increase in the recovery of sphalerite with the addition of TO can be ascribed to the influence of TO on the surface hydrophilicity/hydrophobicity of sphalerite.

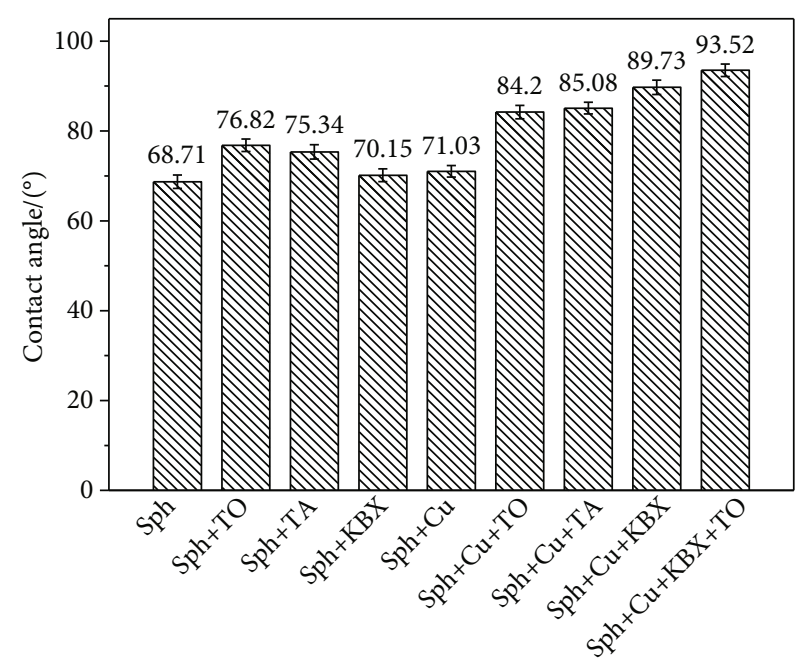

FIGURE 8: Contact angle of sphalerite treated with different flotation reagents $\left(\mathrm{pH}=7.3\right.$; TO: $10 \mathrm{mg} / \mathrm{L}$; TA: $10 \mathrm{mg} / \mathrm{L} ; \mathrm{CuSO}_{4}: 10 \mathrm{mg} / \mathrm{L}$; KBX: $10 \mathrm{mg} / \mathrm{L})$.

3.2. Contact Angle Measurement. The results from the microflotation tests indicate that the flotation recovery of sphalerite significantly increased with the presence of TO in the pulp. Usually, the flotation behavior of minerals is relevant to the surface hydrophilicity/hydrophobicity, which can be reflected by the contact angle. In this work, the contact angle of sphalerite treated with different flotation reagents was measured using the method described by Xie et al. [27]. The results are presented in Figure 8.

The contact angle of natural sphalerite at a $\mathrm{pH}$ of 7.3 was $68.71^{\circ}$, which is closed to the value reported by Subrahmanyam et al. [28]. After treatment with $10 \mathrm{mg} / \mathrm{L}$ TO, the contact angle of sphalerite was increased from $68.71^{\circ}$ to $76.82^{\circ}$, indicating that the hydrophobicity of sphalerite was enhanced by the addition of TO. Similar results were observed when TO was replaced with TA. In addition, the contact angle of sphalerite was $70.15^{\circ}$ when it was treated with $10 \mathrm{mg} / \mathrm{L} \mathrm{KBX}$, which was not significantly different from that of natural sphalerite $\left(68.71^{\circ}\right)$ and lower than the contact angle of sphalerite treated with TO or TA. After activation by $\mathrm{CuSO}_{4}$, the contact angle of sphalerite was increased from $68.71^{\circ}$ to $71.03^{\circ}$. The contact angle of sphalerite was further increased from $68.71^{\circ}$ to $84.20^{\circ}$ and $85.08^{\circ}$, respectively, when treated with $10 \mathrm{mg} / \mathrm{L} \mathrm{TO}$ and TA, indicating that the hydrophobicity of $\mathrm{Cu}$-activated sphalerite was also significantly improved by the addition of TA or TO. However, the contact angle of $\mathrm{Cu}$-activated sphalerite with the addition of $\mathrm{KBX}$ was $89.73^{\circ}$, which is greater than the contact angle with the addition of TO or TA. These results indicate that $\mathrm{KBX}$ plays a predominant role in the hydrophobicity of sphalerite when activated by $\mathrm{CuSO}_{4}$. Meanwhile, the measured contact angle of $\mathrm{Cu}-$ activated sphalerite with the addition of both KBX and TO was $93.52^{\circ}$, which is greater than that treated with $\mathrm{Cu}+\mathrm{KBX}, \mathrm{Cu}+\mathrm{TO}$, or $\mathrm{Cu}+\mathrm{TA}$, indicating that there was a synergistic effect between $\mathrm{KBX}$ and $\mathrm{TO}$ on the $\mathrm{Cu}$ activated sphalerite surface. This is in good agreement with the microflotation results. 


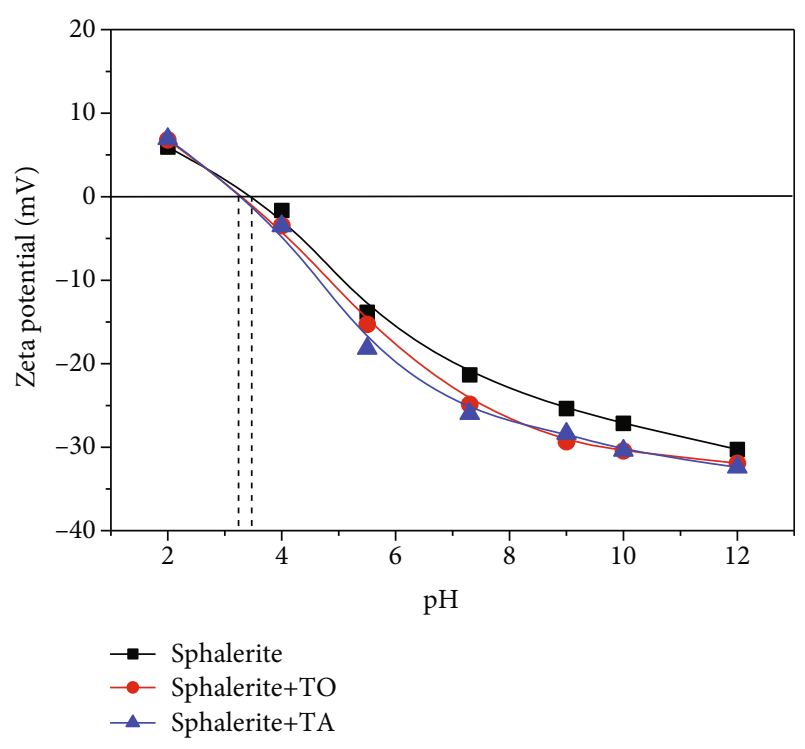

Figure 9: Effect of TO or TA on the zeta potential of sphalerite (TO: $10 \mathrm{mg} / \mathrm{L}$; TA: $10 \mathrm{mg} / \mathrm{L}$ ).

3.3. Zeta Potential. Contact angle measurements illustrate that the surface hydrophobicity of sphalerite was remarkably improved by treatment with TO or TA, indicating that there is an interaction between sphalerite and TO. The alteration of the mineral surface charge is an important reference for revealing the interactions between the mineral particle and the flotation reagent. In this work, the zeta potential was employed to investigate the changes in electrical properties of mineral surfaces. The zeta potential of sphalerite with the addition of TO or TA as a function of $\mathrm{pH}$ is shown in Figure 9.

For sphalerite, the zeta potential was decreased with increasing $\mathrm{pH}$ with the absence of TO or TA in the suspension. The isoelectric point (IEP) of sphalerite without other reagents was approximately 3.3 , which is similar to the value reported by Laskowski et al. and Deng et al. [21, 29]. Without the addition of reagents, the ions determining the electrical property of the sphalerite surface were principally protons and hydroxyl ions. However, the zeta potential of sphalerite at the $\mathrm{pH}$ ranges of 3.0 to 12.0 was further decreased when TO or TA was present in the suspension. The IEP of sphalerite was also decreased from 3.3 to 3.1. This finding indicated that TO or TA was adsorbed onto the mineral surface, but the zeta potential of sphalerite does not change significantly due to the low solubility and the nonionic nature of TO or TA. In addition, the alteration tendencies of the zeta potential with the addition of TO or TA are almost identical.

3.4. FT-IR Spectrum. Microflotation and contact angle measurements demonstrated that the recovery and hydrophobicity of sphalerite were significantly improved with the presence of TO or TA in the pulp. To further investigate the interaction between TO and the sphalerite surface, the FT-IR spectra of sphalerite treated with TA or TO were measured, and the results are shown in Figure 10.

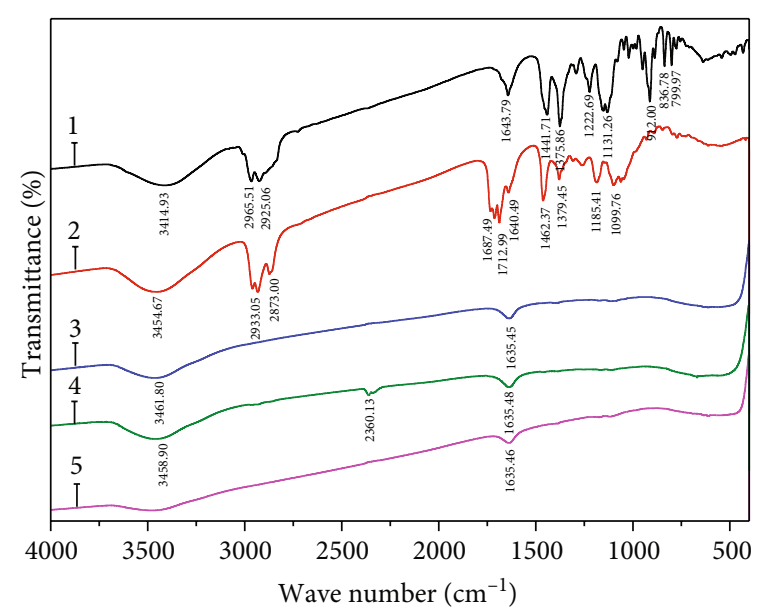

FIgURE 10: FT-IR spectrum of sphalerite treated with TA or TO (1: TA; 2: TO; 3: sphalerite; 4: sphalerite+TA; 5: sphalerite+TO).

In the FT-IR spectrum of TA, the absorption peak at $3414.93 \mathrm{~cm}^{-1}$ is attributed to the stretching vibration of $-\mathrm{OH}$, which represents the characteristic absorption peak of TA. The peaks at $2965.51 \mathrm{~cm}^{-1}$ and $2925.06 \mathrm{~cm}^{-1}$ are ascribed to the asymmetric and symmetric stretching vibrations of $-\mathrm{CH}$, respectively. The peak at $1643.79 \mathrm{~cm}^{-1}$ is due to the stretching vibration of the $-\mathrm{C}=\mathrm{C}-$ of cyclohexene. The peak at $1441.71 \mathrm{~cm}^{-1}$ can be identified as the bending vibration of $\mathrm{CH}$. For $\mathrm{TO}$, the positions of the characteristic absorption peaks in the FT-IR spectrum are almost identical to those of TA, which suggests that the primary component of TO is TA. Only a few differences were detected in the FTIR spectrum of TO, which could be attributed to the influence of nonpolar oil in TO. In the FT-IR spectrum of sphalerite, the absorption peak at $1635.45 \mathrm{~cm}^{-1}$ represents the bending vibration of $-\mathrm{OH}$ adsorbed on the sphalerite surface, which is derived from the adsorption of Zn-hydroxyl complexes on the sphalerite surface. The peak at $610.84 \mathrm{~cm}^{-1}$ can be identified as the stretching vibration of Zn-S [30, 31]. After treatment with TA, however, a broad peak at $3458.90 \mathrm{~cm}^{-1}$ was detected on the sphalerite surface, which represents the stretching vibration of $-\mathrm{OH}$ in TA. The results indicate that part of the TA in the pulp can adsorb on the sphalerite surface through the interaction between the polar group - $\mathrm{OH}$ of TA and the sphalerite surface; the similar results were found in the FT-IR spectrum of sphalerite treated with TO. However, no new absorption peak was found on the sphalerite surface when TA or TO interacted with the sphalerite surface, which indicates that no new compounds were formed and that the adsorption of TA or TO on the sphalerite surface may only be physical adsorption. The physical adsorption of flotation reagents on a mineral surface is usually weak and unstable.

3.5. SEM-EDS. During the microflotation of sphalerite, the agglomeration was observed when TO or TA was added to the pulp. The agglomeration of mineral particles is caused by the hydrophobic interactions between the mineral particles, and the agglomeration can be enhanced by an increase in surface hydrophobicity [32]. In this study, the 

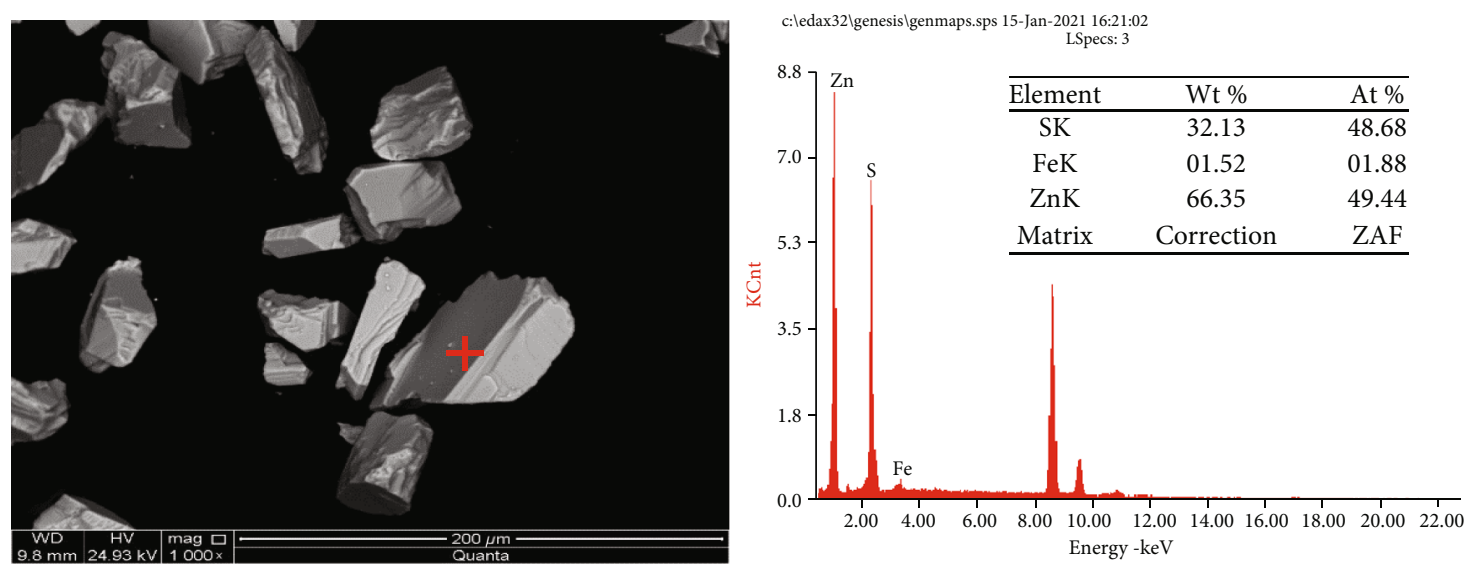

(a)
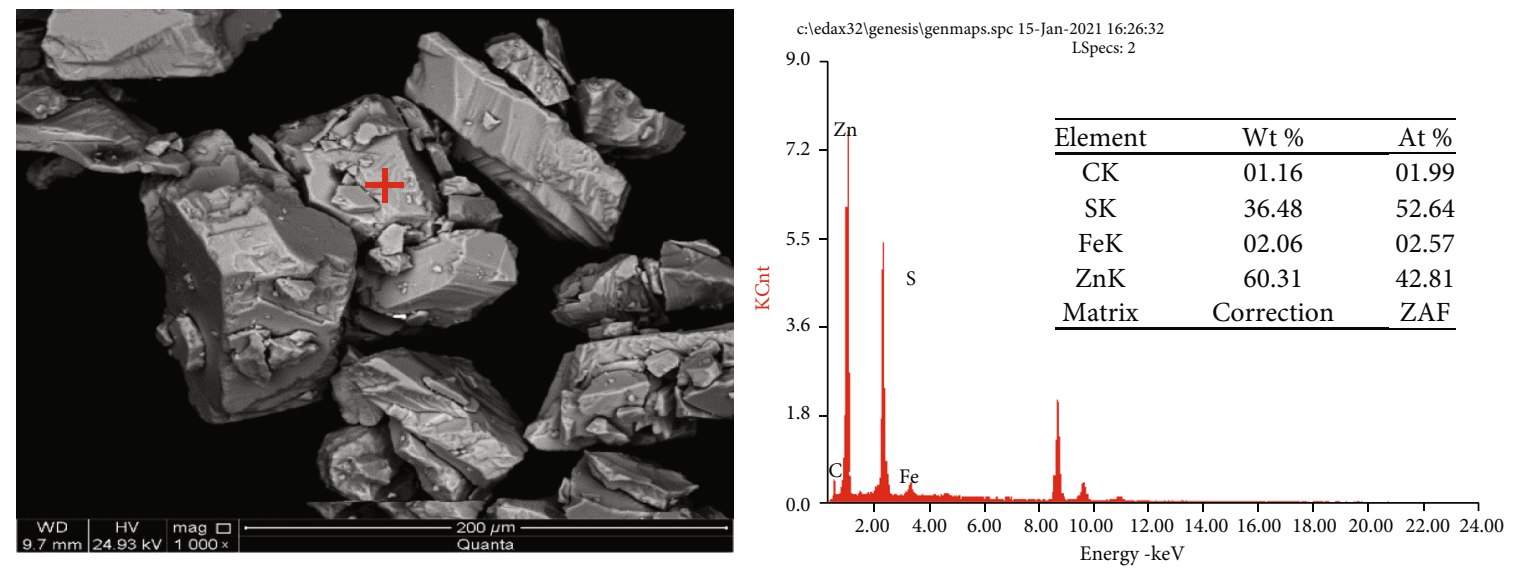

(b)

FIgURE 11: SEM-EDS images of sphalerite treated with TO: (a) without the addition of TO; (b) with the addition of $10 \mathrm{mg} / \mathrm{L}$ TO.

agglomeration of sphalerite particles in the presence of TO was investigated using SEM-EDS. SEM-EDS images are shown in Figure 11.

Figure 11 shows that without the addition of TO, most of the sphalerite particles were naturally dispersed and only a few fine particles adhered to each other due to the hydrophobic interaction between the mineral particles. Song et al. suggested that under the specified $\mathrm{pH}$ conditions, common sulfide minerals such as galena, chalcopyrite, and sphalerite can produce hydrophobic agglomeration due to their hydrophobic interactions [33]. In addition, SEM-EDS indicates that without the addition of TO, the element composition on the sphalerite surface is mainly $\mathrm{Zn}, \mathrm{S}$, and $\mathrm{Fe}$, which is basically consistent with the results from the chemical composition of Table 1. However, more agglomerations of sphalerite particles with a large size were observed with the addition of $10 \mathrm{mg} / \mathrm{L}$ TO compared without the addition of TO, which indicated that the hydrophobic agglomeration of sphalerite particles was significantly promoted due to the influence of TO. Furthermore, it was observed that part of the sphalerite surface was covered by fine sphalerite particles due to the influence of TO. Besides, the carbon peak with an atomic concentration of $1.87 \%$ in Figure 11(b) was detected on the sphalerite surface after the addition of TO. The carbon elements detected on the sphalerite surface were derived

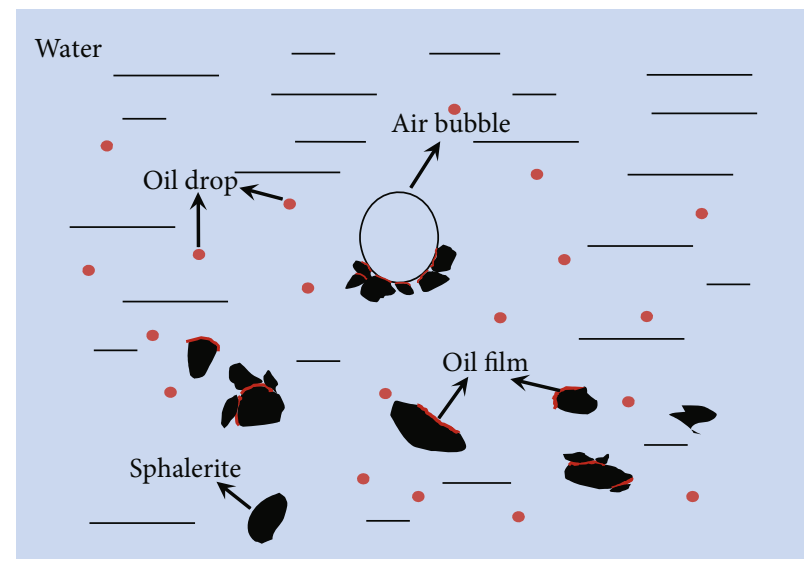

Figure 12: Diagrammatic sketch of the influence of TO on the flotation of sphalerite.

from TO because no reagents were added during the conditioning stage, which suggests that TO can be adsorbed on the sphalerite surface.

Zhang et al. reported that nonpolar oil promotes the hydrophobic agglomeration of sulfide mineral particles by the formation of oil films on mineral surfaces, and the adhesion forces between mineral particles involved in 
hydrophobic agglomeration were increased by the nonpolar oil [34]. Considering the results from FT-IR and SEM-EDS, it can be concluded that due to the low solubility of TO in the water phase, the adsorption of TO on the sphalerite surface was achieved by the formation of an oil film on the surface. Therefore, the surface hydrophobicity and flotation recovery of sphalerite were improved. At the same time, the hydrophobic agglomeration of sphalerite particles was significantly promoted because of the bridging role of TO. The influence of TO on the flotation of sphalerite is illustrated in Figure 12.

Therefore, we can infer that except for the role of froth entrainment, the influence of the frother TO on the flotation behavior of sphalerite may be another important factor affecting the misreporting of sphalerite in concentrates during the selective separation of galena from sphalerite.

\section{Conclusions}

$\mathrm{TO}$, as the most common flotation frother in China, not only has excellent foaming ability but also has an important influence on the floatability of sphalerite. Compared with KBX, the flotation recovery of the unactivated sphalerite significantly increased with the addition of TO in the pulp; the higher the dosage of TO, the higher the recovery of sphalerite. When activated by $\mathrm{CuSO}_{4}$, the recovery of sphalerite was also enhanced by the addition of TO, but the increase in the recovery of sphalerite with the addition of TO was lower than that with the addition of KBX. TA, the predominant component of $\mathrm{TO}$, was responsible for the increase in the recovery of sphalerite. The surface hydrophobicity of sphalerite and $\mathrm{Cu}$-activated sphalerite was remarkably enhanced by the addition of TO or TA to the pulp, thereby enhancing the flotation recovery. In addition, TO could also be adsorbed on the sphalerite surface in the formation of the oil film due to the low solubility in the pulp, and the agglomeration of sphalerite particles was significantly enhanced due to the bridging role of $\mathrm{TO}$ adsorbed on the sphalerite surface.

\section{Data Availability}

The data used to support the findings of this study are included within the article.

\section{Conflicts of Interest}

The authors declare that they have no conflicts of interest.

\section{Authors' Contributions}

Bo Yang and Xian Xie conceived of and designed the experiments; Lingyun Huang prepared the samples and performed the experiments; Xiong Tong analyzed the data; Bo Yang, Xian Xie, and Lingyun Huang contributed to the writing and revising of the paper.

\section{Acknowledgments}

This research was funded by the Yunnan Fundamental Research Project (No. 2019FH001(-091)), the Opening Research Project from the State Key Laboratory of Complex Nonferrous Metal Resources Clean Utilization (No. CNMRCUKF1902), and the National Natural Science Foundation of China (No. 51964024).

\section{References}

[1] H. Han, Y. Hu, W. Sun et al., "Fatty acid flotation versus BHA flotation of tungsten minerals and their performance in flotation practice," International Journal of Mineral Processing, vol. 159, pp. 22-29, 2017.

[2] D. Chipfunhu, G. Bournival, S. Dickie, and S. Ata, "Performance characterisation of new frothers for sulphide mineral flotation," Minerals Engineering, vol. 131, pp. 272-279, 2019.

[3] W. Kracht, Y. Orozco, and C. Acuña, "Effect of surfactant type on the entrainment factor and selectivity of flotation at laboratory scale," Minerals Engineering, vol. 92, pp. 216-220, 2016.

[4] J. G. Wiese and C. T. O'Connor, "An investigation into the relative role of particle size, particle shape and froth behaviour on the entrainment of chromite," International Journal of Mineral Processing, vol. 156, pp. 127-133, 2016.

[5] L. Wang, Y. Peng, and K. Runge, "Entrainment in froth flotation: the degree of entrainment and its contributing factors," Powder Technology, vol. 288, pp. 202-211, 2016.

[6] L. Wang, Y. Peng, and K. Runge, "The mechanism responsible for the effect of frothers on the degree of entrainment in laboratory batch flotation," Minerals Engineering, vol. 100, pp. 124-131, 2017.

[7] B. Yang, X. Tong, X. Xie, and L. Y. Huang, "Insight into the effect of galvanic interactions between sulfide minerals on the floatability and surface characteristics of pyrite," Physicochemical Problems of Mineral Processing, vol. 57, no. 2, pp. 24-33, 2021.

[8] P. Vallejos, J. Yianatos, C. Matamoros, and F. Díaz, "Mineral solids transport in a two-dimensional flotation froth," Minerals Engineering, vol. 138, pp. 24-30, 2019.

[9] G. J. Jameson and C. Emer, "Coarse chalcopyrite recovery in a universal froth flotation machine," Minerals Engineering, vol. 134, pp. 118-133, 2019.

[10] M. Cao and Q. Liu, "Reexamining the functions of zinc sulfate as a selective depressant in differential sulfide flotation-The role of coagulation," Journal of Colloid and Interface Science, vol. 301, no. 2, pp. 523-531, 2006.

[11] C. Li, K. Runge, F. Shi, and S. Farrokhpay, "Effect of flotation conditions on froth rheology," Powder Technology, vol. 340, pp. 537-542, 2018.

[12] J. Wiese and P. Harris, "The effect of frother type and dosage on flotation performance in the presence of high depressant concentrations," Minerals Engineering, vol. 36-38, pp. 204210, 2012.

[13] S. M. Bulatovic, 3-Frothers, in Handbook of Flotation Reagents, S. M. Bulatovic, Ed., Elsevier, Amsterdam, 2007.

[14] C. Li, K. Runge, F. Shi, and S. Farrokhpay, "Effect of flotation froth properties on froth rheology," Powder Technology, vol. 294, pp. 55-65, 2016.

[15] P. Amelunxen, R. LaDouceur, R. Amelunxen, and C. Young, "A phenomenological model of entrainment and froth 
recovery for interpreting laboratory flotation kinetics tests," Minerals Engineering, vol. 125, pp. 60-65, 2018.

[16] D. H. Hoang, S. Heitkam, N. Kupka, A. Hassanzadeh, U. A. Peuker, and M. Rudolph, "Froth properties and entrainment in lab-scale flotation: a case of carbonaceous sedimentary phosphate ore," Chemical Engineering Research \& Design, vol. 142, pp. 100-110, 2019.

[17] L. Wang, Y. Peng, K. Runge, and D. Bradshaw, "A review of entrainment: mechanisms, contributing factors and modelling in flotation," Minerals Engineering, vol. 70, pp. 77-91, 2015.

[18] X. Zheng, N. W. Johnson, and J. P. Franzidis, "Modelling of entrainment in industrial flotation cells: water recovery and degree of entrainment," Minerals Engineering, vol. 19, no. 11, pp. 1191-1203, 2006.

[19] Z. Huangfu, S. A. Khoso, W. Sun, Y. Hu, C. Chen, and Q. Zhang, "Utilization of petrochemical by-products as a new frother in flotation separation of molybdenum," Journal of Cleaner Production, vol. 204, pp. 501-510, 2018.

[20] H. Pakdel, S. Sarron, and C. Roy, " $\alpha$-Terpineol from hydration of crude sulfate turpentine oil," Journal of Agricultural and Food Chemistry, vol. 49, no. 9, pp. 4337-4341, 2001.

[21] Z. B. Deng, X. Tong, A. L. Valdivieso, X. Wang, and X. Xie, "Collectorless flotation of marmatite with pine oil," Rare Metals, vol. 36, no. 2, pp. 147-154, 2017.

[22] R. Zhang, "Gas chromatographic analysis of flotation frother," Yunnan Metallurgy, vol. 27, no. 6, pp. 44-51, 1998.

[23] T. Nuorivaara and R. Serna-Guerrero, "Unlocking the potential of sustainable chemicals in mineral processing: improving sphalerite flotation using amphiphilic cellulose and frother mixtures," Journal of Cleaner Production, vol. 261, article 121143, 2020.

[24] N. Zhang, X. Chen, and Y. Peng, "Effects of froth properties on dewatering of flotation products- A critical review," Minerals Engineering, vol. 155, article 106477, 2020.

[25] S. M. Bulatovic, 2-Collectors, in Handbook of Flotation Reagents, S. M. Bulatovic, Ed., Elsevier, Amsterdam, 2007.

[26] D. Fornasiero and J. Ralston, "Effect of surface oxide/hydroxide products on the collectorless flotation of copper-activated sphalerite," International Journal of Mineral Processing, vol. 78, no. 4, pp. 231-237, 2006.

[27] X. Xie, K. Hou, B. Yang, and X. Tong, "Activation of sphalerite by ammoniacal copper solution in froth flotation," Journal of Chemistry, vol. 2016, 6 pages, 2016.

[28] T. V. Subrahmanyam, C. A. Prestidge, and J. Ralston, "Contact angle and surface analysis studies of sphalerite particles," Minerals Engineering, vol. 9, no. 7, pp. 727-741, 1996.

[29] J. S. Laskowski, Q. Liu, and Y. Zhan, "Sphalerite activation: flotation and electrokinetic studies," Minerals Engineering, vol. 10, no. 8, pp. 787-802, 1997.

[30] K. Yang, S. Li, L. Zhang et al., "Microwave roasting and leaching of an oxide-sulphide zinc ore," Hydrometallurgy, vol. 166, pp. 243-251, 2016.

[31] K. Yang, L. Zhang, C. Lv et al., "Role of sodium citrate in leaching of low-grade and multiphase zinc oxide ore in ammoniaammonium sulfate solution," Hydrometallurgy, vol. 169, pp. 534-541, 2017.

[32] M. Mirnezami, L. Restrepo, and J. A. Finch, "Aggregation of sphalerite: role of zinc ions," Journal of Colloid and Interface Science, vol. 259, no. 1, pp. 36-42, 2003.
[33] S. Song, A. Lopez-Valdivieso, J. L. Reyes-Bahena, and H. I. Bermejo-Perez, "Hydrophobic flocculation of sphalerite fines in aqueous suspensions induced by ethyl and amyl xanthates," Colloids and Surfaces A: Physicochemical and Engineering Aspects, vol. 181, no. 1-3, pp. 159-169, 2001.

[34] T. ZHANG, W.-q. QIN, C.-r. YANG, and S.-p. HUANG, "Floc flotation of marmatite fines in aqueous suspensions induced by butyl xanthate and ammonium dibutyl dithiophosphate," Transactions of Nonferrous Metals Society of China, vol. 24, no. 5, pp. 1578-1586, 2014. 